\title{
As controvérsias entre as elites na imprensa. Questões sobre a política externa durante transição democrática brasileira nas páginas da revista VEJA.
}

\author{
Disputes within the elite in the press. \\ Foreign policy during Brazilian democratic transition \\ as seen in VEJA magazine.
}

\author{
Jacqueline Ventapane Freitas \\ Universidade Federal Fluminense \\ jacventapane@gmail.com
}

\begin{abstract}
Resumo: No período da transição política brasileira, após os anos da ditadura militar, a imprensa aparece na memória sobre a transformação política do país como um de seus principais atores políticos, espaço da expressão das demandas da sociedade civil e dos movimentos sociais que ganhavam força com a liberalização. No entanto, essa memória de resistência obscurece o papel importante dos meios de comunicação, como as empresas privadas, na representação dos interesses de setores das elites. A revista $V E J A$ atuou, desde seu início, na defesa de interesses que nem sempre estavam de acordo com os do regime, partilhando valores dessas elites, se inserindo nas disputas para prevalecer seu próprio projeto de país. Essa ambivalência pode ser percebida na disputa em torno das decisões da política externa daquele período, que geraram impactos importantes na política doméstica.
\end{abstract}

Palavras Chave: Transição política; Imprensa; Política Externa; Revista VEJA.

Abstract: In the period of political transition in Brazil, after the years of the military dictatorship, the press appears in memory about the political transformation of the country as one of its main political actors, the expression of the space demands of civil society and social movements that gained strength with the liberalization. However, this memory of resistance obscures the important role of the media, as private companies, in representing the interests of elites' sectors. The magazine VEJA has served, since its inception, in the defense of interests that were not always according to the government, sharing values of these elites, if entering in the disputes to prevail its own country project. This ambivalence can be perceived in contention around the foreign policy decisions of that period, which generated important impacts on domestic policy.

Keywords: Political transition; Press; Foreign Policy; VEJA magazine. 
Nesta nota de pesquisa, serão apresentados alguns dos aspectos para uma análise da atuação da imprensa no processo de transição política que ocorreu após os anos da ditadura militar brasileira, estudo que vem sendo desenvolvido em um projeto sobre a relação entre imprensa e política naquele período. A partir de decisões sobre questões da política externa dos dois últimos governos militares - Ernesto Geisel (1974-1979) e João Baptista de Figueiredo (1979-1985), publicadas na revista semanal de informações VEJA, da Editora Abril, esse estudo pretende discutir o papel dos meios de comunicação como espaços de representações de interesses, mas, também, como atores políticos da redemocratização, em sua condição de elites simbólicas. Nesse duplo papel, a revista, naturalizando sua atuação dentro dos parâmetros da "neutralidade" e da "objetividade" jornalística, na realidade, defendeu um projeto de democracia limitada e não inclusiva, que se consolidou com o projeto neoliberal implementado no país a partir dos anos 1990.

Objeto de interpretações diferenciadas entre si, o processo de redemocratização envolve memórias construídas em torno dos diferentes atores políticos. As análises sobre as transições políticas podem ser vistas a partir de três categorias: (1) como fenômenos políticos iniciados pelo Estado, em sua capacidade de antecipação às pressões sociais; (2) transições que se explicam a partir das crises econômicas; e (3) as transições que se iniciam pela mobilização social. ${ }^{1}$ No caso da transição brasileira, a maior parte dos estudos define seu modelo como uma transição negociada ou pactuada, dentro da primeira dessas categorias. Nesse modelo, o governo autoritário assume o papel central no processo de redemocratização, estabelecendo a agenda da abertura e negociando, com a oposição, as regras do novo quadro político que se estabelece.

Dentro da perspectiva conhecida como transitologia, ${ }^{2}$ a adoção do compromisso entre as elites define-se como condição fundamental para uma transição democrática bem sucedida, um jogo controlado por um pequeno número de atores "confiáveis", construindo uma teoria baseada no "argumento de moderação": é preciso que haja moderação das demandas e dos comportamentos da mobilização popular para que a transição democrática, definida pelas escolhas das elites, não seja ameaçada. Contudo, como afirma Bermeo, ${ }^{3}$ a moderação, discurso presente não apenas nas análises da transitologia, mas naqueles enfatizados pelos próprios construtores dos processos de transição, não é um pré-requisito para a constituição de uma democracia. Segundo a autora, esse tipo discurso fundamenta-se sobre as atitudes das elites. $^{4}$

No entanto, esse processo, mais do que apenas um pacto, envolve duas dinâmicas atuando no sistema político: a da negociação entre as elites e das pressões da sociedade sobre o Estado ditatorial, constituindo uma transição resultante do choque de dois projetos distintos de mudança. ${ }^{5}$ No caso da ditadura militar brasileira, podem ser percebidos dois lugares opostos da memória: aquele que ocupa 0

\footnotetext{
${ }^{1}$ DINIZ, Eli. A transição política no Brasil: uma reavaliação da dinâmica da abertura. Revista Dados, vol. 28, nํ. 3, 1985, pp.330-332.

2 Para a transitologia, a reinstauração de um regime democrático não depende de pré-requisitos, sendo relegados a um segundo plano os fatores sociais, econômicos e culturais, pela atenção voltada às "estratégias dos atores relevantes" e à conduta da mudança política. MONCLAIRE, Stéphane. Democracia, transição e consolidação: precisões sobre conceitos bestializados. Revista de Sociologia e Política. Curitiba, 17, Nov. 2001, pp. 61-74.

3 BERMEO, Nancy. Myths of Moderation: Confrontation and Conflict during Democratic Transitions. Comparative Politics, Vol. 29, no. 3, Transitions to Democracy: A Special Issue in Memory of Dankwart A. Rustow, Apr. 1997, pp. 305322. Disponível

em:

http://www.constitutionnet.org/files/Bermeo\%20Myths\%20of\%20Moderation_Confrontation\%20and\%20Conflict\%20Durin g\%20Democratic\%20Transition.pdf. Acesso em: 15/07/2013.

${ }_{5}^{4} \mathrm{O}$ discurso de moderação é evidente nas defesas da redemocratização feitas pelo empresariado brasileiro.

5 DINIZ, Eli; BOSCHI, Renato R. A consolidação democrática no Brasil: atores políticos, processos sociais e intermediação de interesses. In: DINIZ, Eli et. al. Modernização e consolidação democrática no Brasil: dilemas da Nova República. São Paulo: Vértice/ Editora Revista dos Tribunais, 1989, pp. 15-75.
} 
espaço da lembrança das torturas, das perseguições, do medo, da censura, com a contrapartida da luta contra o arbítrio e pelo retorno da democracia ao país; e o do silêncio, mais que o esquecimento, daqueles que constroem uma memória seletiva de uma autoimagem essencialmente democrática, ignorando sua relação próxima aos ideais que eram a base de uma sociedade autoritária. ${ }^{6}$

Nesse contexto da transição, a imprensa aparece na memória sobre a transformação política do país como um dos principais atores sociais no confronto com o regime, espaço da expressão das demandas da sociedade civil e dos movimentos que foram ressurgindo com o processo de liberalização inicial, dentro da distensão estabelecida com a ascensão de Ernesto Geisel e de Golbery do Couto e Silva, seu chefe da Casa Civil, ao poder. Contudo, essa memória de resistência permite que se mantenham na sombra as complexas relações entre os meios de comunicação, empresas privadas com interesse no lucro, e o governo ditatorial, associando a imagem da ação da luta individual de jornalistas no embate com o regime à própria atuação da instituição imprensa como ator coletivo, ignorando, desta forma, seu papel na representação de valores e interesses de setores das elites e não da sociedade como um todo. De acordo com Caparelli, ${ }^{7}$ a relação da ditadura militar brasileira com os meios de comunicação foi uma conjugação de conflitos e contradições de interesses que se deram entre os próprios jornalistas, os proprietários dos meios de comunicação e os anunciantes, incluindo-se, nessa relação, o público que compra a notícia.

Na relação que se estabelece entre a imprensa e a política, quando uma transição entra no caminho do conflito institucionalizado das oposições, os meios de comunicação participam da socialização das novas regras do jogo democrático, ampliando o espaço de comunicação entre a elite e o público. ${ }^{8}$ No entanto, no quadro das transições latino-americanas, essa "nova" democracia, manteve a persistência de um caráter autoritário na perspectiva que enfrenta uma ameaça constante de sabotagem por parte das classes sociais e economicamente dominantes. ${ }^{9}$ De acordo com Backzo, ${ }^{10}$ as situações de conflito entre poderes concorrentes estimulam a "invenção de novas técnicas de combate no domínio do imaginário", onde se confrontam dois movimentos opostos que envolvem a representação engrandecedora de seu próprio poder com a desvalorização do adversário, e "intensifica a produção de imaginários sociais concorrentes e antagonistas, e em que as representações de uma nova legitimidade e de um futuro diferente proliferam e ganham difusão e agressividade".

Essa ambivalência pode ser vista nas próprias definições sobre o projeto de redemocratização que era defendido através da grande imprensa, incluindo a VEJA. É nesse quadro que se desenvolve a presente pesquisa. A imprensa brasileira, ao mesmo tempo em que abriu espaço para reivindicações de setores da sociedade civil, assumiu um papel dentro do quadro das elites na defesa de um projeto de democracia que, antes de ser inclusivo, deixava de fora esses mesmos movimentos sociais. Ao mesmo tempo, essa imprensa foi construindo essa memória de resistência e de fortalecimento de seu papel como poder fiscalizador.

Ainda que reconhecendo a atuação privada dos meios de comunicação na defesa de seus interesses, na tradição dos estudos sobre o papel da imprensa, não apenas no processo de

\footnotetext{
${ }^{6}$ ROLLEMBERG, Denise; QUADRAT, Samantha (orgs). A construção social dos regimes autoritários: Brasil e América Latina. Rio de Janeiro: Civilização Brasileira, 2011, vol. 2, pp. 13-14.

7 CAPARELLI, Sergio. Autoritarismo e meios de comunicação no Cone Sul. In MELO, José Marques de (org.). Comunicação e transição democrática. Porto Alegre: Mercado Aberto/Intercom, 1985, pp. 234-245.

${ }^{8}$ GUNTHER, Richard e MUGHAN, Anthony (ed.). Democracy ant the Media. A comparative perspective. Cambridge: Cambridge University Press, 2000.

${ }^{9}$ BORON, Atilio. Estado, capitalismo y democracia en America Latina. Buenos Aires: Clacso, 2003, pp. 26-27.

${ }^{10}$ BACZKO, Bronislaw. A imaginação social. In: Enciclopédia Einaudi, s. 1. Lisboa: Imprensa Nacional/Casa da Moeda, Editora Portuguesa, 1985.
} 
democratização, mas durante toda a ditadura, prevalece uma interpretação a partir dos limites da censura, em todos os seus meios - judicial, econômico ou político, e da autocensura que serviu como parâmetro após a suspensão daqueles meios legais. Segundo Abreu, ${ }^{11}$ o jornalismo internacional foi uma alternativa para que os veículos de comunicação escapassem da censura imposta à imprensa durante a ditadura no país. Entretanto, ao mesmo tempo, as notícias internacionais apareciam nos veículos como questionamento às decisões políticas no campo externo.

$\mathrm{Na}$ hipótese aqui apresentada, mais do que uma maneira de escapar da censura imposta aos veículos, as questões externas serviam como motores para as controvérsias entre as próprias elites, na tentativa de influenciar o governo no atendimento aos seus interesses. Os dois últimos governos militares, correspondentes à distensão e à abertura, tiveram que dar respostas aos efeitos causados pelas crises internacionais ao projeto de desenvolvimento nacional brasileiro. Temas quase sempre distantes da discussão do grande público, mantidos nos espaços restritos das elites política, estatal e econômica, as políticas implementadas pelo governo na definição das diretrizes de sua inserção internacional geraram impactos importantes no quadro da política doméstica.

Duroselle considera que a política interna dos Estados é um dos principais elementos de compreensão da política exterior, já que "não há nenhum ato de política externa que não tenha um aspecto da política interna". ${ }^{12}$ Desta forma, é possível compreender que o alcance e a realização dos objetivos da política externa de cada Estado estejam vinculados aos interesses dos diversos grupos que dela procuram fazer parte no contexto interno. Segundo Milza, o problema de identidade que envolve esses grupos "vincula-se [ao] dos modelos externos que, em alguns países, esta ou aquela facção da classe política e da opinião pública podem reivindicar". ${ }^{13}$

No caso da ditadura brasileira, duas correntes de propostas de desenvolvimento - aquela que se associava às relações políticas, econômicas e geopolíticas com os Estados Unidos; e outra que reforçava a ideia de um desenvolvimento autônomo, baseado nas forças da nação que procura estabelecer uma autonomia política dentro do sistema internacional, e de formação de um forte núcleo econômico internamente - refletiam o modelo de projeto interno para o país. Nesse quadro, podemos recuperar a perspectiva de Vizentini, ${ }^{14}$ que afirma serem as decisões da política externa defendidas por alguns setores hegemônicos do bloco de poder que dão suporte ao governo, mas não o seu conjunto, e que grupos de interesses conseguem influir em determinadas áreas do processo decisório, que se desenrola a partir de uma relação dialética entre as políticas externa e interna.

As políticas exteriores do Pragmatismo Responsável e da Diplomacia do Universalismo, nos governos Ernesto Geisel e João Figueiredo, respectivamente, foram instrumentos de inúmeras disputas entre setores das elites brasileiras, envolvendo os projetos externos e internos do regime que iniciava seu processo de redemocratização. A necessidade de manter o suporte econômico da ditadura, abalado pelas crises internacionais daqueles anos, era fundamental para que a transição seguisse os ditames do grupo do poder. O projeto de redemocratização teria estreitas ligações com os problemas derivados da crise econômica em que o país mergulhara em decorrência dos efeitos da crise internacional do petróleo de

\footnotetext{
${ }_{11}^{11}$ ABREU, Alzira Alves de (org.). Mídia e política no Brasil: jornalismo e ficção. Rio de Janeiro: Editora FGV, 2003, p. 26.

12 DUROSELLE, Jean-Baptiste. Todo império perecerá. Brasília: Ed. UnB; São Paulo: Imprensa Oficial do Estado, 2000, p. 57.

${ }^{13}$ MILZA, Pierre. Política interna e política externa. In: RÉMOND, René. Por uma história política. Tradução Dora Rocha, 2a. Ed., Rio de Janeiro: Editora FGV, 2003, p. 373.

14 VIZENTINI, Paulo Fagundes. A Política Externa do Regime Militar Brasileiro: Multilateralização, Desenvolvimento e Construção de uma Potência Média (1964-1985). Porto Alegre: Editora da Universidade/ UFRGS, 1998.
} 
1973. Na argumentação de Vizentini, ${ }^{15}$ a descompressão surgia como necessária para o controle da radicalização social diante de um quadro de instabilidade.

Geisel recebera o legado problemático do "milagre econômico", que incluía a dependência do afluxo de capitais estrangeiros, que sofreram um grande impacto com a crise que havia causado uma forte recessão nos países industrializados. Nesse sentido, era preciso que o governo alterasse os rumos da até então política externa do país para dar conta, não apenas de criar alternativas ao fornecimento do petróleo, mas para responder às necessidades de um mercado interno que não absorvia sua produção. Externa e internamente, as novas linhas do Pragmatismo Responsável elaborado pelo chanceler Antônio Francisco Azeredo da Silveira e pelo próprio presidente enfrentaram a oposição dos Estados Unidos e de segmentos conservadores da sociedade brasileira.

O presidente seguinte, João Baptista de Figueiredo, assumiu em um contexto ainda mais adverso, tanto interna quanto externamente, com um quadro internacional abalado por uma nova crise do petróleo, o aumento dos juros, consequência da resposta dos Estados Unidos à própria crise e à nova política da Era Reagan, e a crescente dívida externa decorrente dessas crises, que atingiu, especialmente, a América Latina. O novo chanceler, Ramiro Saraiva Guerreiro, assumiu a continuidade das diretrizes da política exterior do pragmatismo, autointitulada, agora, Diplomacia do Universalismo, estreitando a aproximação como o chamado Terceiro Mundo, mas reduzindo os confrontos mais diretos com os Estados Unidos, apresentando um recuo em direção ao projeto africano e ampliando os vínculos com os países da América do Sul.

No campo doméstico, a liberalização iniciada no governo anterior, abriu espaço para novos movimentos, que vieram acompanhados das reivindicações de trabalhadores, com greves de grande expressão nacional que assustaram ainda mais aqueles segmentos conservadores das elites nacionais. Neste momento, era decretada a anistia no país e era feita a reforma partidária que acabou com o bipartidarismo e abriu a possibilidade para a criação de novos partidos. Além disso, ganhava força o ativismo político da Igreja e as manifestações de estudantes. As forças de direita da chamada "linha-dura", contrárias ao projeto de redemocratização, assumiram uma oposição violenta que se traduziu em atentados, sequestros e espancamentos de líderes dos movimentos sociais e ataques às bancas de jornal e veículos de imprensa alternativa.

A imprensa, que teria encontrado o espaço para fugir da censura nas notícias internacionais, fazia, ao mesmo tempo, uma associação dessas críticas às questões de política doméstica e às de caráter econômico, especialmente nas temáticas que envolviam os problemas energéticos e os conflitos entre o empresariado nacional e os interesses externos, estabelecendo um debate com o próprio governo no campo de sua política exterior. Contudo, essas críticas iam até os limites que não alteravam o status quo de uma democratização controlada, que excluía, principalmente, os movimentos sociais organizados. Os eventos internos e externos que aconteceram nos dois últimos governos militares da transição levaram a que os grupos se apresentassem de maneira mais definida, transpondo suas demandas para além do círculo fechado do poder e travando uma luta por sua afirmação pública.

Para Hallin, ${ }^{16}$ a cobertura da imprensa é um reflexo das divisões das elites. A partir de sua análise dos jornais e a relação entre seus efeitos na opinião pública estadunidense, o autor observou que existe um

\footnotetext{
${ }^{15}$ VIZENTINI, Paulo. Relações internacionais do Brasil - de Vargas a Lula, 3ạ. Ed., São Paulo: Editora Fundação Perseu Abramo, 2008, p. 49.

${ }^{16}$ HALLIN, Daniel C. The "uncensored war". The Media and Vietnam. University of California Press, 1989.
} 
modelo de atuação ou interpretação que afeta a própria ação da imprensa. Sua atuação se daria a partir de um modelo dividido em três regiões, representadas por círculos concêntricos, cada uma delas regida por diferentes padrões jornalísticos: uma região central denominada Esfera da Controvérsia Legítima, o espaço em que as diversas posições políticas são apresentadas e discutidas e, também, onde reinam a objetividade e o equilíbrio como virtudes supremas do campo jornalístico, que aparece, por sua vez, como um mediador e não um crítico ou defensor de uma das partes do debate político, mas que enfatiza o papel das forças hegemônicas no sentido de delinear o que é aceitável ou permitido dizer na mídia; a região da Esfera do Consenso, que engloba os temas não considerados nem pelos jornalistas e nem pela maioria da sociedade como algo controverso; e a Esfera do Desvio, em que os atores políticos e os jornalistas rejeitam visões que desafiam o consenso político, com a imprensa passando diretamente a expor, condenar e excluir o que viola ou desafia esse consenso e onde a suposta neutralidade deixa de existir.

De acordo com Sponholz, uma ditadura pode impor os limites de uma controvérsia legítima, contudo, mesmo em regimes democráticos, esses se veem diante de limites, sejam eles de ordem moral ou política, que definem os consensos. Como diz a autora, as "controvérsias se diferenciam de acordo com o conteúdo, com os atores, com o espaço e com a forma de participação do público" e, do ponto de vista midiático, uma controvérsia "é um instrumento de condução de um conflito". ${ }^{17}$

A revista $V E J A$, criada quase que concomitante com o fechamento do regime, em setembro de 1968, assumiu uma memória que reforça a censura, os espaços ocupados pelas árvores-símbolo da Editora Abril ou os anjos e demônios dos editoriais. Porém, desde seus primeiros números, sua posição política e ideológica era de defesa da iniciativa privada, da crítica ao estatismo crescente, especialmente com Ernesto Geisel, e de uma democracia dentro da ordem. Apesar de não ter se expressado com muita ênfase na associação incondicional com os Estados Unidos, foi incisiva na crítica ao alinhamento diplomático com as questões dos países em subdesenvolvimento, principalmente, na questão africana e palestina. Por outro lado, mantinha seu apoio ao governo, especialmente, nos conflitos internos com os grupos contrários à redemocratização do país, que defendiam a predominância da geopolítica ocidental sob a hegemonia dos Estados Unidos, mas rejeitava a intervenção estatal na economia, pregando a livre iniciativa como o projeto mais adequado para o novo Brasil democrático.

$\mathrm{E}$, nesse contexto, a VEJA, mais do que assumir o papel de um espaço autônomo de expressão de demandas, atuava como ator na defesa de interesses nem sempre coadunados com os do governo, partilhando valores com setores das elites e se inserindo nas disputas sobre o projeto de país que se pretendida com o fim do regime militar. Especialmente no governo Geisel, a revista acentuava suas críticas à postura do Pragmatismo Responsável da condução da política externa pelo Itamaraty, que acentuava um distanciamento do tradicional alinhamento aos Estados Unidos. É importante ressaltar que a censura que incidia sobre a revista somente seria suspensa em 1976. Os ataques mais diretos à política, principalmente, do chanceler Antônio Francisco Azeredo da Silveira viriam durante o período em que o veículo esteve sob censura.

Como afirmam Rollemberg e Quadrat, há uma valorização dos movimentos de resistência aos regimes autoritários e ditaduras que acaba por relegar a um patamar secundário a formação do consenso e do consentimento que se deu ao redor do regime, mesmo nos momentos de questionamento de seu modelo político. Segundo as autoras,

\footnotetext{
${ }^{17}$ SPONHOLZ, Liriam. O papel do jornalismo nas controvérsias. Estudos em Jornalismo e Mídia, Ano VII N. 1, Janeiro a Junho de 2010, pp. 165-172. Disponível em: http://www.periodicos.ufsc.br/index.php/jornalismo. Acesso em: 15/05/2013.
} 
interessa verificar concretamente como os consensos foram criados; como as acomodações de interesses fizeram-se em regimes autoritários através de mecanismos traduzidos em ganhos materiais e/ou simbólicos para as sociedades. Se a resistência e a memória da resistência sempre identificaram as ditaduras às tiranias, estas foram reivindicadas até mesmo como salvadoras da própria democracia, dos valores nacionais e sociais, como o único caminho, o fio condutor da transformação radical da sociedade. Em diferentes circunstâncias, a democracia é que foi rejeitada. ${ }^{18}$

A Editora Abril, a partir de sua principal revista de informação, participa dos debates na defesa de um projeto neoliberal, que acabou por se consolidar a partir dos anos 1990. Tendo como eixo a crítica à aproximação com o Terceiro Mundo, no contraponto de seu afastamento ao tradicional alinhamento com os Estados Unidos, mesmo que sob os mecanismos da censura, defendia os interesses dos setores alinhados com esse projeto, partilhando os valores das elites da qual fazia parte. E um dos eixos do programa defendido foi a expansão das privatizações e a diminuição da estatização, em um confronto que vinha desde os anos do início da transição de Geisel.

Os indícios da atuação da imprensa, durante a transição política brasileira, ao questionar o modelo político, mas não os modelos econômicos e sociais do regime militar, remetem à sua configuração dentro dessa esfera da controvérsia legítima. A partir da liberalização da imprensa, vozes de oposição encontram espaços para se manifestarem. No entanto, nem todas tinham a mesma amplitude, especialmente, se fossem confrontados os modelos de democratização política e o de democratização econômica.

Jacqueline Ventapane Freitas: Doutoranda em Ciência Política pela Universidade Federal Fluminense (UFF), Graduada e Mestre em História Política pela UERJ. Co-organizadora dos livros "Tempo negro, temperatura sufocante: Estado e Sociedade no Brasil do Al-5", "O Brasil de João Goulart. Um projeto de nação", "CD-ROM Cadernos do Terceiro Mundo", autora de artigos sobre imprensa e política. É membro do Laboratório de Estudos sobre a Política Externa Brasileira da UFF e sócia-fundadora da associação Espaço Cultural Diálogos do Sul.

\footnotetext{
${ }^{18}$ ROLLEMBERG e QUADRAT, Op. Cit, p. 17.
} 